\title{
Evaluation of Three Medium Throughput Flow Cytometers for Monitoring People Living with HIV in Resources Limited Laboratories: How to Choose?
}

\author{
André Inwoley ${ }^{1,2^{*}}$, Aimé Cézaire Adiko ${ }^{2,3}$, Mathieu Kabran ${ }^{1,2}$, Roséline Aboli-Affi ${ }^{2}$, Ahmed Diomande ${ }^{2}$, Franck Wozan $^{2}$ and Bamory Dembele ${ }^{2,3}$ \\ ${ }^{1}$ Diagnostic and Research Center on AIDS and Infectious Diseases, University Hospital of Treichville, Abidjan, Ivory Coast \\ ${ }^{2}$ Faculty of Pharmacy, Department of Hematology and Immunology, University Félix Houphouet Boigny, Abidjan, Ivory Coast \\ ${ }^{3}$ Center of Blood Transfusion Laboratory, Treichville, Abidjan, Ivory Coast \\ "Corresponding author: Inwoley A, Diagnostic and Research Center on AIDS and Infectious Diseases, University Hospital of Treichville, Abidjan, Ivory Coast, Tel: +225 \\ 421273 73; E-mail: andre.inwoley@ufrspb.ci
}

Received date: November 15, 2016; Accepted date: January 13, 2017; Published date: January 20, 2017

Copyright: @ 2017 Inwoley KA, et al. This is an open-access article distributed under the terms of the Creative Commons Attribution License, which permits unrestricted use, distribution, and reproduction in any medium, provided the original author and source are credited.

\begin{abstract}
Objective: Absolute and percentage CD4+ T-lymphocytes counts are useful in monitoring people living with HIV. In spite of point-of-care development, CD4 testing in some laboratories of resources-limited countries still use flow cytometers from many manufacturers. We evaluated three flow cytometers (FACSCOUNT CD4/CD4\%, GUAVA Auto CD4/CD4\%, CYFLOW Counter ${ }^{\circledR}$ CD4/CD4\%) and brought out choice criteria according to laboratory resources.
\end{abstract}

Methods: CD4 percent and absolute count obtained with $180 \mathrm{HIV-infected} \mathrm{patients} \mathrm{(adults} \mathrm{and} \mathrm{children)} \mathrm{with}$ evaluated platforms (FACSCOUNT CD4/CD4\%, GUAVA Auto CD4/CD4\%, CYFLOW Counter CD4/CD4\%) were compared with those provided by FACSCalibur TruCount $\circledast$. Agreement was analyzed using Bland-Altman analysis. We also carried out a Comparative analysis of technical and operational characteristics to identify strengths and weaknesses of each tested cytometer.

Results: The median CD4 percentage and absolute count obtained with FACSCOUNT and CYFLOW were similar to those of FACSCALIBUR. By contrast, GUAVA showed higher values. Bland-Altman analysis did not show measurement error. However, GUAVA and CYFLOW gave a relative high bias with mean difference respectively -69 and $+27 C D 4$ cells $/ \mu$. The overall bias of CD4 percentage were $>5 \%$ for the evaluated cytometers. There was a good interclass agreement (Kappa $\geq 0.78$ ) and good measurement precision (coefficient of variation <10\%) with the 3 cytometers. Only FACSCOUNT showed good stability $(C V<5 \%)$ even for stained and unstained samples within 24 and 48 hours after blood collection. FACSCOUNT, GUAVA and CYFLOW have good technical performances.

Conclusion: Though we found differences in their operational characteristics, it appears very important to know how to use these kinds of cytometers before making a choice for peripheral laboratory in limited-resources countries.

Keywords: HIV; CD4; Flow cytometer; FACSCount; Guava; CyFlow

\section{Introduction}

Human Immunodeficiency Virus (HIV) and Acquired Immunodeficiency Syndrome (AIDS) pandemic have severely affected the health and deteriorated improvement in life expectancy in the world; particularly in countries with high prevalence of infection.

The highest number of people living with HIV (PLWH) is in subSaharan Africa with 24.7 million (23.5 million-26.1 million) people. Next are Asia and Pacific with 4.8 million (4.1 million-5.5 million) PLWH [1]. HIV gradually destroys immune system cells (including CD4 cells, a type of lymphocyte), weakening the immune system and resulting in AIDS and death from cancer or opportunistic infections [2].

Like developed countries, many efforts are undertaken in countries with limited resources to improve access to antiretroviral therapy for people living with HIV. Successful management of health care of people infected with HIV in resource-limited countries is possible only if ART program is associated with affordable laboratory servicing particularly CD4 lymphocyte monitoring $[3,4]$.
Indeed, absolute count and CD4 percentage and viral load are the fundamentals and independent markers in the decision to initiate antiretroviral therapy (ART) for HIV-positive people [5,6]. It also assesses the effectiveness of ART whose medium-term objective is to restore the immune system. The high cost of viral load monitoring has led sub-Saharan practitioners, to consider this marker as non-essential for initiation of ART but useful in case of immunological failure in the treatment process.

During past decade many manufacturers have provided Point-ofCare (POC) technologies for CD4 and viral load and some of them have been evaluated and used in many resource- limited countries [7-9]. These POC have been dedicated to the clinical team, especially when the number of patients is not too high [10-12].

Despite the development of POC, CD4 enumeration has always been done by conventional flow cytometer (FCM) technology because of its precision, accuracy, reproducibility and easy use in laboratory [13-15].

Many flow cytometers have been tested [16-24]. However, some of this first generation has a few limitations: (i) it was not possible to get 
Citation: Inwoley A, Adiko AC, Kabran M, Aboli-Affi R, Diomande A, et al. (2017) Evaluation of Three Medium Throughput Flow Cytometers for Monitoring People Living with HIV in Resources Limited Laboratories: How to Choose?. J Immuno Biol 2: 118. doi:10.4172/2476-1966.1000118

Page 2 of 8

CD4 percentage which is very important in children monitoring or (ii) the use of FCM software requires good computer skills by the operator.

In response to these concerns, flow cytometers manufacturers have developed new technologies, already tested in some countries $[14,25,26]$.

Therefore, this study aimed at assessing these new platforms, comparing the absolute and percentage values of CD4+ T-lymphocytes count obtained on these FCM with those of a reference flow Cytometer, and their technical and operational characteristics.

\section{Material and Methods}

\section{Blood samples}

This study was carried out from January to October 2009. We used one hundred and eighty (180) tubes of blood collected from HIVpositive adults and paediatrics patients, aging from 9 months to 67 years. Blood samples were the remaining routine specimens kept at room temperature and drawn within $8 \mathrm{~h}$. Specimen have been selected from three centers (96 from the General Hospital of Koumassi, 89 General Hospital of Port-Bouet and 18 from the Pediatrics Service of the University Hospital of Treichville, Abidjan), in order to have at least 50 subjects in each category of CDC classification: $\quad(<200$ cells $/ \mathrm{mm}^{3}, 200 \leq \mathrm{CD} 4<500$ cells $/ \mathrm{mm}^{3}, \geq 500$ cells $/ \mathrm{mm}^{3}$ ) [27]. Samples were carried from the clinical center to the laboratory in a cooler condition with icepack to maintain temperature between 18 and $22^{\circ} \mathrm{C}$.

We did not include: samples which provided absolute CD4 more than 3,000 cells $/ \mathrm{mm}^{3}$ on FACSCALIBUR (Becton Dickinson, San Jose, USA) or samples untested on at least one of the 3 evaluated flow cytometers.

Each patient or his legal representative signed a consent form to approve their participation to the study after reading an information form. As the study did not require additional phlebotomy, we only got the agreement of scientific committee of the Pharmacy school because the study was part of students' memoires.

\section{Cytometer and platform evaluated}

The 3 evaluated cytometers were FACSCount CD4/CD4\% (Becton Dickinson, San Jose, USA), GUAVA Auto CD4/CD4\% (Millipore USA; previously Guava Technologies, Hayward, CA, USA), Cyflow Counter CD4/CD4\% (Sysmex Germany, previously Partec GmbH, Munster, Germany). Table 1 shows the main characteristics of the three evaluated flow cytometers. FACSCalibur (Becton Dickinson, San Jose, USA) was used as reference cytometer.

\begin{tabular}{|c|c|c|c|}
\hline Characteristics & FACSCOUNT & GUAVA & CYFLOW \\
\hline Numbers of PMT & 2 & 2 & 2 \\
\hline Laser & Convection-cooled Laser & Green diode Laser & Green solide laser \\
\hline Optics parameters & $\mathrm{FSC} / \mathrm{FL} 1$ et FL2 & $\mathrm{FSC} / \mathrm{FL} 1$ et $\mathrm{FL} 2$ & SSC/FL1et FL2 \\
\hline Software & FACSCount CD4/3 Software Version 1.0 & Cytosoft 6.1 & CyView-1.7 \\
\hline Software using & Simple/automatic « gating » & Simple/automatic « gating » & Simple/manual « gating» \\
\hline Panel & CD4-PE/CD14-PE-Cy5/CD15 PE-Cy5 & $\begin{array}{l}\text { CD4 PE/CD3-CD56 CD16-CD19 } \\
\text { PECy5 }\end{array}$ & CD4-PE/CD45-PE-Dy647 \\
\hline Training days required & 2 & 2 & 2 \\
\hline Absolute count Technic & Beads & Volumetric & Volumetric \\
\hline Open System & No & Yes & Yes \\
\hline $\begin{array}{l}\text { Number of tests made for reagent (showed } \\
100 \text { tests) }\end{array}$ & 100 & 95 & 95 \\
\hline Incubation time ( $\min )$ & 30 & 45 & 15 \\
\hline Processing time for a test $(\mathrm{min})$ & $35-50$ & $50-60$ & $25-30$ \\
\hline CD4 result & absolute CD4/CD4\% & absolute CD4/CD4\% & absolute CD4/CD4\% \\
\hline Analysis modes & Automatic & Automatic or manual & Manual \\
\hline Controls data archiving & Yes & Yes & Yes \\
\hline Archiving of test data & 100 last tests & Yes (no limit) & 125000 last tests \\
\hline Number of test for one operator per day & 75 & 60 & 50 \\
\hline
\end{tabular}

Table 1: Technical and operational characteristics of evaluated flow cytometers.

FACSCount ${ }^{\bullet}$ (Becton Dickinson, San Jose, USA): It is a single platform Flow cytometer for CD4+T lymphocytes counting, a closed system using 2 color-monoclonal Antibodies ( $\mathrm{mAb}$ ) reagents in a twin tube containing reference beads. Additional control beads are available. 
The optical and electronic systems of FACSCount can analyze 2 fluorescences in addition to Forward Scatter (FSC).

Guava $^{\bullet}$ (Millipore, previously Guava Technologies, Hayward, CA, USA): The Guava is a single platform cytometer with a system for volumetric enumeration of $\mathrm{T}$ lymphocytes $\mathrm{CD} 4+$ in the absence of sheath liquid and beads. The optical and electronic systems of Guava analyse 2 fluorescences in addition to Forward Scatter (FSC). Control beads Guava Check $^{\oplus}$ are used for daily quality control.

Cyflow Counter (Sysmex Germany, previously Partec GmbH, Munster, German): The Cyflow Counter is a single platform flow cytometer equipped with a system for volumetric enumeration of $\mathrm{CD} 4+\mathrm{T}$ lymphocytes in the absence of beads. The optical and electronic systems of the Cyflow Counter ${ }^{\infty}$ could analyze both fluorescences (orange and red) in addition to the morphological characteristics of granularity (SSC). The built-in software of the new Cyflow Counter ${ }^{\circ}$ is CyView-1.7 software.

FACSCalibur system (Becton Dickinson, San Jose, USA): Conventional multicolor flow cytometer for CD4+ $\mathrm{T}$ cell counting either in single platform using reference beads or double platform with hematology analyzer. The optical and electronic FACSCalibur ${ }^{\circledR}$ systems can analyse 3 or 4 different fluorescences in addition to cell size (FSC) and granularity (SSC).

\section{CD4 $\mathrm{T}$ cell measurements}

All the blood samples were tested simultaneously for CD4 counting on evaluated cytometers (Guava ${ }^{\oplus}$, Cyflow Counter ${ }^{\oplus}$, FACSCount ${ }^{\circledR}$ ) and reference flow cytometer (FACSCalibur ${ }^{\circ}$ ) according to the operating procedures required by the manufacturers. Each sample was tested once on each device to evaluate the performance compared to FACSCalibur ${ }^{\oplus}$ cytometer.

For FACSCount evaluation we used the "BD FACSCount CD4 Reagents kit". In brief $50 \mu \mathrm{l}$ of EDTA whole blood was added to the FACSCount ${ }^{\ominus}$ reagent tubes containing a mixture of monoclonal antibody (CD4-PE, CD14-PECy5, CD15-PECy5) with a fluorescent dye core, sample diluents and reference beads. The samples were vortexed and incubated in the dark for $30 \mathrm{mn}$ at room temperature. Then, $50 \mu \mathrm{l}$ of fixative solution was added to each tube and both were incubated for $5 \mathrm{mn}$ in the dark at room temperature. Then samples were run on the FACSCount ${ }^{\circledR}$ after vortexing.

The built-in software dedicated to this kit (FACSCount CD4/3 Software Version 1.0 06/07) was used for data analysis. The measuring range is from 50 to $2,000 \mathrm{CD} 4 / \mu \mathrm{l}$. CD4 $\mathrm{T}$ cell count was expressed in absolute number and in percentage.

For Guava evaluation, the Guava Auto CD4/CD4\% kit was used. It contains: (i) a mixture of anti-human lymphocyte antibody (CD3/ CD56/CD16/CD19) conjugated to the tandem PE-Cy5 fluorochrome for lymphocytes $(\mathrm{NK}+\mathrm{T}+\mathrm{B})$ recognizing, (ii) a $\mathrm{CD} 4$ monoclonal antibody conjugated to phycoerythrin dye. We distributed $10 \mu$ of the Guava ${ }^{\oplus}$ Auto CD4/CD4\% reagent cocktail ([CD3+CD56/ $\mathrm{CD} 19+\mathrm{CD} 16]-\mathrm{PECy} 5+\mathrm{CD} 4-\mathrm{PE})$ and $10 \mu \mathrm{l}$ of the total blood were distributed in microfuge tubes. The mixture was vortexed for 2 to 3 seconds. After incubation for $30 \mathrm{mn}$ at room temperature in the dark, $380 \mu \mathrm{l}$ of Lysis solution $1 \mathrm{X}$ Guava ${ }^{\circ}$ were added making a total sample volume of $400 \mu \mathrm{l}$. The tube was vortexed and incubated again for 15 $\mathrm{mn}$. The samples were finally run on Guava and CD4 T cell count was obtained in absolute number and in percentage.
The analysis on the Guava flow cytometer is performed by the builtin AFTP software CytoSoft Autogating 6.1 which has an automatic and manual gating. The flow cytometer control on the Guava was achieved with the Guava ${ }^{\oplus}$ CHECK control beads.

For CD4+ T-lymphocytes count on Cyflow Counter ${ }^{\circ}$, we used the $\mathrm{CD} 4 \%$ easy count reagent kit (PE/PE-Dy647) containing CD4-PE/ CD45-PE-Dy647 antibody panel for this assessment. For internal quality control, count check green beads of a known concentration were run every day to make sure that the laser was properly aligned and the analyzer was functioning optimally. Thus, $10 \mu \mathrm{l}$ of reagent 1 (CD4-PE), $10 \mu \mathrm{l}$ of reagent 2 (CD45-PE-Dy647) and $20 \mu \mathrm{l}$ of the total blood were distributed in each tubes. The samples were gently mixed and incubated for 15 minutes at room temperature in the dark and then $800 \mu$ dilution buffer 1 and $800 \mu$ dilution buffers 2 were added and finally samples were read in $10 \mathrm{mn}$ on the Cyflow CyView-7 software which has a complete manual gating. The results were expressed in percentage and absolute values of CD4 per $\mu$ l.

The FACSCalibur was used as predicate instrument for CD4 T cell counting in the study by single-platform. The BD TRITEST CD3FITC/CD4-PE/CD45-PerCP kit with Trucount BD tubes (catalog ${ }^{\circ}$ 342444 ) were used for CD4 count. For this, $50 \mu$ of the whole blood was added into TruCount tubes containing a fixed number of polystyrene reference beads and $10 \mu \mathrm{l}$ of monoclonal antibody cocktail containing CD3-FITC, CD4-PE and CD45-PerCP. After $15 \mathrm{mn}$ of incubation at room temperature, red blood cells were lysed by adding $500 \mu \mathrm{RBC}$ lysing solution (Becton Dickinson). The samples were run on the FACSCalibur ${ }^{\circledR}$ and the data were analysed using MultiSet $^{\oplus}$ Version 1.0.1 software. The Calibrate beads ${ }^{\oplus}$ of Becton Dickinson were used for voltage setting and fluorescence compensation with FACSCOMP ${ }^{\circledR}$ software.

We used four operators, one for each FCM in three laboratories: the General Hospital of Koumassi for Guava ${ }^{\oplus}$, the General Hospital of Port-Bouet for FACSCount ${ }^{\circ}$ and CeDReS for CyFlow ${ }^{\circ}$ and FACSCalibur'. These operators have been trained by FCM suppliers and these laboratories participate to external control quality of QASI. In addition, CeDReS also participate to UK NEQAS program; witch certifies the use of FACSCalibur ${ }^{\bullet}$ as reference system.

\section{Assessment of the precision of $\mathrm{CD} 4 \mathrm{~T}$ cell counting and aged blood stability}

For this purpose, we selected 3 blood samples in each of the 3 immunological different categories previously described.

To assess the Intra-run precision of the 3 cytometers, each of the 9 specimens was acquired 10 times successively and average coefficients of variations (\%CVs) were calculated. The precision was expressed as the coefficient of variance $(\mathrm{CV})$ obtained by dividing the standard deviation $(\mathrm{SD})$ of all the measurements by the mean $(\mathrm{CV} \%=\mathrm{SD} \times 100 /$ mean).

To assess the stability of preparations (unstained or stained samples), 3 blood samples in each of the 3 immunological different categories samples were tested on the day of collection. The stained and remaining samples were stored at $4^{\circ} \mathrm{C}$ and tested again after $24 \mathrm{~h}$ and $48 \mathrm{~h}$. 
Citation: Inwoley A, Adiko AC, Kabran M, Aboli-Affi R, Diomande A, et al. (2017) Evaluation of Three Medium Throughput Flow Cytometers for Monitoring People Living with HIV in Resources Limited Laboratories: How to Choose?. J Immuno Biol 2: 118.doi:10.4172/2476-1966.1000118

Page 4 of 8

\section{Statistical analysis}

Whereas, CD4+ T-cell counts values do not follow a normal distribution according to Agostino-Pearson test; nonparametric statistical tests were used.

The agreement between an evaluated and the reference methods as proposed by Bland and Altman [28,29] was illustrated by plotting the average of CD4+ T-lymphocytes counts from the evaluated and reference methods displayed on X; against the difference between the two methods shown on Y. The average difference between the two methods, referred to as "bias", is marked on the graph by horizontal line and Limits of Agreement (LOA) with 95\% Confidence Interval (CI) were also calculated.

The kappa test, using concordance kappa coefficient permits to evaluate the accuracy of the classification of CD4+ T-lymphocytes in the different categories by the Cytometer studied from the reference Cytometer (interclass agreement). The kappa value was determined according to the classification suggested by LANDIS and KOCH [30].

The Coefficient of Variation (CV) was calculated and used to define agreement between each evaluated method. The method was accurate if $\mathrm{CV}<10 \%$.

To evaluate the stability of the different evaluated methods and preparation, we calculated the relative bias. Stability was considered as satisfactory when the mean relative biases expressed in percentage is less than or equal to $10 \%$ between Day 1 and Day 0 (phlebotomy Day) and less than or equal to $15 \%$ between D0 and D2.

For each sample, relative bias in percentage between the results obtained at $\mathrm{Di}(\mathrm{i}=1$ or 2$)$ and the results obtained on the day of blood sampling (D0) was equal to $100 x$ [(Di-D0)/D0].

We finally compared Performance Scores (technical and operational) of evaluated cytometers.

\section{Results}

Globally, we used 180 blood samples from 35 children ( $<15$ years) and 145 adults for the assessment. The sex-ratio of this population was 0.43 .

During assessment with Guava ${ }^{\oplus}$, automatic gating did not give result for 29 samples $(16.1 \%)$ and the generated message indicating that the number of total lymphocytes was low. The lymphocyte number of these samples was effectively lower than 1,000 cells $/ \mathrm{mm}^{3}$. However, the results were obtained by manual gating under the administrator profile. Also FACSCount ${ }^{\circledR}$ did not provide CD4 percentages for $10.6 \%$ of samples (19/180).

The median percentage and absolute CD4 T-lymphocyte values obtained with FACSCount ${ }^{\circledR}$ and $\mathrm{Cy}$ low $^{\circledR}$ systems were similar to those of FACSCalibur ${ }^{ø}$ (Figure 1). By contrast, Guava gave higher values in comparison to reference cytometer.

For the absolute $\mathrm{CD} 4$ count, Guava ${ }^{\circledR}$ and $\mathrm{Cyflow}^{\circledR}$ gave a relative high bias with respectively -69 and 27 CD 4 cell per $\mu$. The bias of CD4 percentage was relatively low and less than $2 \%$ for the 3 cytometers on the whole and in each CD4 strata. But Cyflow gave a mean bias of $3 \%$ for $\mathrm{CD} 4$ percentage greater than $15 \%$.

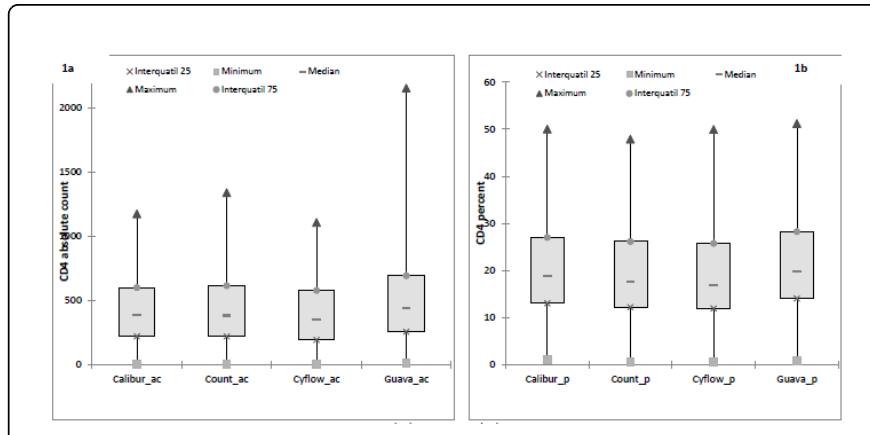

Figure 1: Comparison of the general distribution absolute count (1a) and percent (1b) of CD4+ T lymphocyte values provided by different cytometers on a box-plot.

Figure 2 provides an agreement overview between evaluated methods and the FACSCalibur ${ }^{\circ}$ analysis. The Bland-Altman plots showed no measurement error even if Guava showed a tendency to overestimate the absolute CD4 count compared to FACSCalibur ${ }^{\circledR}$ when CD4 values are high.

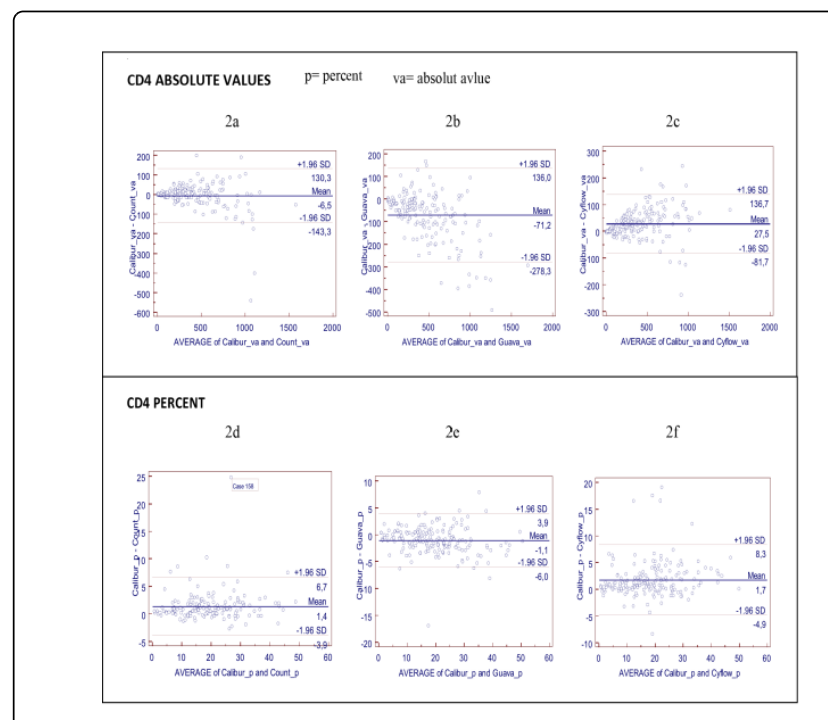

Figure 2: Bland-Altman bias plots of the difference between FACSCount, Guava, Cyfloe Counter systems and reference system, FACSCalibur for CD4 absolute count (a,b,c) and (percent d,e,f).

Interclass agreement of absolute values was good with Guava $(\mathrm{kappa}=0.78)$ and very good with $\mathrm{Cyflow}^{\circ}$ (kappa=0.83) and FACSCount $^{\circ} \quad(\mathrm{kappa}=0.88)$. Compared to FACSCalibur ${ }^{\oplus}$, the percentage of correctly classified subjects was $91 \%$ for the FACSCount ${ }^{\circ}, 82 \%$ for the Guava ${ }^{\circledR}$ and $86 \%$ for the Cyflow ${ }^{\circ}$. Overall, the inter-class agreement of $\mathrm{CD} 4$ percentage was very good with the 3 evaluated flow cytometers (kappa $>0.80$ ) and the percentage of subjects properly classified was $88 \%, 91 \%$ and $86 \%$ respectively for FACSCount $^{\circ}$, Guava ${ }^{\oplus}$ and Cyflow ${ }^{\oplus}$.

The results of the precision study of the three evaluated cytometers are reported in Table 2. The Coefficient variation was good (below $10 \%$ ) for GUAVA $^{\star}$ and Cyflow $^{\star}$ and very good (below 5\%) for FACSCount ${ }^{\circ}$. The blood stability study results are shown in Table 3 . 
Citation: Inwoley A, Adiko AC, Kabran M, Aboli-Affi R, Diomande A, et al. (2017) Evaluation of Three Medium Throughput Flow Cytometers for Monitoring People Living with HIV in Resources Limited Laboratories: How to Choose?. J Immuno Biol 2: 118. doi:10.4172/2476-1966.1000118

Page 5 of 8

For FACSCount ${ }^{\circ}$, stained and unstained preparation was stable 24 and $48 \mathrm{~h}$ after blood collection (mean relative bias below 5\%) both for CD4 absolute count and percentages.

\begin{tabular}{|c|c|c|c|c|}
\hline \multirow{2}{*}{\multicolumn{2}{|c|}{ T-CD4+ Category }} & \multicolumn{3}{|l|}{ CV (\%) } \\
\hline & & \multirow{2}{*}{$\begin{array}{l}\text { FACSCount } \\
3.98\end{array}$} & \multirow{2}{*}{$\begin{array}{l}\text { Guava } \\
9.25\end{array}$} & \multirow{2}{*}{$\begin{array}{l}\text { Cyflow } \\
4.9\end{array}$} \\
\hline \multirow{3}{*}{ Absolute value } & $\leq 200$ & & & \\
\hline & $(200-500)$ & 4.19 & 5.36 & 6.9 \\
\hline & $\geq 500$ & 4.06 & 4.11 & 8.98 \\
\hline \multirow{3}{*}{ Percentage } & $\leq 15$ & 1.61 & 6.07 & 3.29 \\
\hline & $(15-25)$ & 2.58 & 5.38 & 2.08 \\
\hline & $\geq 25$ & 1.41 & 2.28 & 3.13 \\
\hline
\end{tabular}

Table 2: Coefficients of Variation (CV) of the precision study of the evaluated flow cytometers

\begin{tabular}{|c|c|c|c|c|c|c|c|}
\hline \multirow{3}{*}{ Samples } & \multirow{3}{*}{ Days } & \multicolumn{6}{|c|}{ Mean relative bias (\%) } \\
\hline & & \multicolumn{3}{|c|}{ Absolute T-CD4+ } & \multicolumn{3}{|c|}{ Percent T-CD4+ } \\
\hline & & FACSCount & GUAVA & Cyflow & FACSCount & GUAVA & Cyflow \\
\hline \multirow{2}{*}{ Stained samples } & D0-D1 & 1.17 & -1.45 & -3.21 & 1.96 & -4.32 & -18.68 \\
\hline & D0-D2 & 0.64 & 32.02 & 1.64 & 1.10 & -10.11 & -38.28 \\
\hline \multirow{2}{*}{$\begin{array}{l}\text { Unstained } \\
\text { samples }\end{array}$} & D0-D1 & -0.97 & 11.81 & -6.86 & 1.42 & 4.52 & -1.67 \\
\hline & D0-D2 & -0.56 & 4.60 & -4.97 & 1.70 & 9.48 & 2.14 \\
\hline
\end{tabular}

Table 3: Stability of samples with evaluated flow cytometers

The stability of stained samples was unsatisfactory with Cyflow ${ }^{\circ}$ for $\mathrm{CD} 4$ percentages at $24 \mathrm{~h}$ and $48 \mathrm{~h}$. For Guava ${ }^{\circ}$, samples were not stable only at $48 \mathrm{~h}$ for $\mathrm{CD} 4$ absolute count and percentage.

The stability of unlabelled samples was satisfactory for Cyflow ${ }^{\oplus}$ (bias below $10 \%$ for D1 and D2) for both CD4 absolute count and percentage. This stability was unsatisfactory for Guava ${ }^{\circ}$ early for CD4 count at $24 \mathrm{~h}$.

Technical and operational performances score of the 3 evaluated cytometers were compared in Table 4.

\section{Discussion}

Since the introduction of Antiretroviral Therapy (ART) in developing countries, the need for alternative technologies of CD4+ Tlymphocytes count has significantly increased. Many simplified and affordable flow cytometers have been produced and manufacturers regularly brought innovations to address some concerns on their technical performances and operational characteristics.

In this study, we assessed and compared the CD4 absolute count and percentages of three flow cytometers platforms; FACSCount ${ }^{\circ} \mathrm{CD} 4 /$ $\mathrm{CD} 4 \%$, Guava Auto CD $4 / \mathrm{CD} 4 \%{ }^{\circ}$ and Cyflow Counter CD $4 / \mathrm{CD} 4 \%{ }^{\circ}$.

\section{Technical performances}

The Comparison of CD4 T-cell absolute and percentage values of the 3 evaluated flow cytometers with those obtained by FACSCalibur ${ }^{\circ}$ showed that results provided by the 3 flow cytometers are similar to FACSCalibur ${ }^{\bullet}$ results.

The agreement between FACSCount ${ }^{\circledR}$ and FACSCalibur ${ }^{\circledR}$ was satisfactory as shown by no anomaly in Bland Altman graph and good inter-class agreement for $\mathrm{CD} 4$ absolute count and percentage. FACSCount ${ }^{\circ}$ had a very satisfactory precision for absolute and percentage values with coefficients of variations less than $5 \%$.

In our context where incidents can occur on sites (power shutdown, delayed delivery of samples or equipment breakdown), it's important to study the stability of the preparation. Our results showed that FACSCount ${ }^{\oplus}$ provided satisfactory results even if stained preparations are kept for $24 \mathrm{~h}$ and $48 \mathrm{~h}$ with bias lower than 5\%. The same performance was obtained for the sample stability. Delaying the CD4 test might be an exception to solve problems but priority will be given to the resolution of the incident.

For Guava, the Bland Altman agreement graph shows tendency to overestimate the absolute results when the values of CD4 increase. In addition, absolute bias increases between Guava ${ }^{\circ}$ and FACSCalibur ${ }^{\circ}$ from low to higher strata. Our results confirmed previous studies reporting that Guava is less accurate at CD4 counts above 500 cells/ $\mu 1$ $[16,20,21,31]$. This difference could be caused by the way of separating monocyte and lymphocyte count which share CD4 on cell surface. Even all the three FCM evaluated used "lymphogating" it's not the same strategy. Guava ${ }^{\circ}$ used CD3/CD56/CD16/CD19 while Cyflow ${ }^{\circ}$ and FACSCount ${ }^{\circ}$ used respectively CD45 and CD14/CD15/Anti DNA. 
Citation: Inwoley A, Adiko AC, Kabran M, Aboli-Affi R, Diomande A, et al. (2017) Evaluation of Three Medium Throughput Flow Cytometers for Monitoring People Living with HIV in Resources Limited Laboratories: How to Choose?. J Immuno Biol 2: 118. doi:10.4172/2476-1966.1000118

Page 6 of 8

\begin{tabular}{|c|c|c|c|c|c|c|c|c|c|c|c|}
\hline & \multirow{2}{*}{ Indicators } & \multirow{2}{*}{ Scores } & \multicolumn{3}{|c|}{ FACSCount } & \multicolumn{3}{|c|}{ Guava } & \multicolumn{3}{|c|}{ Cyflow } \\
\hline & & & count & $\%$ & Total & count & $\%$ & Total & count & $\%$ & Total \\
\hline \multirow{22}{*}{ 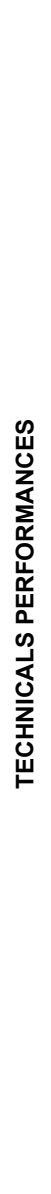 } & \multirow{3}{*}{ Correlation } & $<0.90$ (1) & \multirow{3}{*}{3} & \multirow{3}{*}{3} & \multirow{3}{*}{6} & \multirow{3}{*}{3} & \multirow{3}{*}{3} & \multirow{3}{*}{6} & \multirow{3}{*}{3} & \multirow{3}{*}{3} & \multirow{3}{*}{6} \\
\hline & & $0.90-0.94(2)$ & & & & & & & & & \\
\hline & & $0.95-1(3)$ & & & & & & & & & \\
\hline & \multirow{3}{*}{ Interclass Agreement } & $<0.60$ (1) & \multirow{3}{*}{3} & \multirow{3}{*}{3} & \multirow{3}{*}{6} & \multirow{3}{*}{2} & \multirow{3}{*}{3} & \multirow{3}{*}{5} & \multirow{3}{*}{3} & & \\
\hline & & $0.6-0.80(2)$ & & & & & & & & 3 & 6 \\
\hline & & $0.81-1(3)$ & & & & & & & & & \\
\hline & & $>10 \%(0)$ & & & & & & & & & \\
\hline & Precision & $5-10 \%(1)$ & 2 & 2 & 4 & 1 & 1 & 2 & 1 & 2 & 3 \\
\hline & & $\leq 5 \%(2)$ & & & & & & & & & \\
\hline & & $>10 \%(0)$ & & & & & & & & & \\
\hline & Preparation Stability 24h & $5-10 \%(1)$ & 2 & 2 & 4 & 2 & 2 & 4 & 2 & 0 & 2 \\
\hline & & $\leq 5 \%(2)$ & & & & & & & & & \\
\hline & & $>10 \%(0)$ & & & & & & & & & \\
\hline & Preparation Stability $48 \mathrm{~h}$ & $5-10 \%(1)$ & 2 & 2 & 4 & 0 & 0 & 0 & 2 & 0 & 2 \\
\hline & & $\leq 5 \%(2)$ & & & & & & & & & \\
\hline & & $>10 \%(0)$ & & & & & & & & & \\
\hline & Sample Stability 24h & $5-10 \%(1)$ & 2 & 2 & 4 & 0 & 2 & 2 & 1 & 2 & 3 \\
\hline & & $\leq 5 \%(2)$ & & & & & & & & & \\
\hline & & $>10 \%(0)$ & & & & & & & & & \\
\hline & Sample Stability $48 \mathrm{~h}$ & $5-10 \%(1)$ & 2 & 2 & 4 & 2 & 1 & 3 & 1 & 2 & 3 \\
\hline & & $\leq 5 \%(2)$ & & & & & & & & & \\
\hline & SUBTO & TAL/32 & & & 32 & & & 22 & & & 25 \\
\hline & 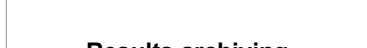 & Limited (1) & & & 1 & & & $\rho_{0}$ & 0 & & 0 \\
\hline & Kesuits arcining & Unlimited (2) & & & 1 & & & 2 & 2 & & 2 \\
\hline & Nhumbon of oton & $>5(1)$ & & & 2 & & & 0 & 1 & & 1 \\
\hline & & $\leq 5(2)$ & & & 2 & & & 2 & 1 & & 1 \\
\hline 苂 & A tomting to & No $(0)$ & & & 1 & & & & & & \\
\hline$\sum_{\substack{\Omega \\
\Omega}}$ & Nurugating & Yes (1) & & & 1 & & & 1 & 0 & & \\
\hline 竞 & 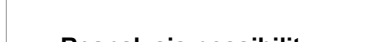 & No $(0)$ & & & 0 & & & 1 & 1 & & 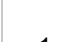 \\
\hline a & 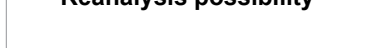 & Yes (1) & & & 年 & & & 1 & 1 & & 1 \\
\hline z & & $<100 \%(1)$ & & & & & & & & & \\
\hline$\underset{\S}{E}$ & Results providing & $100 \%$ after re-analysis $(2)$ & 3 & 1 & 4 & 2 & 2 & 4 & 2 & 2 & 4 \\
\hline 㟧 & & $100 \%$ without re-analysis $(3)$ & & & & & & & & & \\
\hline & Robustness against electrical & No $(0)$ & 2 & & 1 & & & 0 & 1 & & 1 \\
\hline & variation & Yes (1) & & & 1 & & & 0 & 1 & & 1 \\
\hline & SUBTO & TAL/13 & & & 10 & & & 11 & & & 10 \\
\hline & TOTAL/45 & & & & 42 & & & 33 & & & 35 \\
\hline
\end{tabular}

Table 4: Scores of technical and operational performances of evaluated flow cytometers. 
Interclass agreement between Guava ${ }^{\oplus}$ and FACSCalibur ${ }^{\circledR}$ was good for CD4 absolute count (Kappa $=0.78)$ and CD4 percent (Kappa $=0.88$ ). However, only $82 \%$ and $91 \%$ of patients were well classified by the Guava ${ }^{\oplus}$ respectively for CD4 absolute count and CD4 percent. Even Guava $^{\infty}$ precision was satisfactory $(\mathrm{CV}<10 \%)$, the stability study showed that stained preparations kept for $48 \mathrm{~h}$ cannot be used to determine CD4 values. Thus, sample must be stained the day of phlebotomy since it cannot be stored.

There was a good agreement between Cyflow ${ }^{\circ}$ and FACSCalibur ${ }^{\bullet}$ as shown by Bland Altman graphs. In addition, the means bias was lower than $30 \mathrm{CD} 4 / \mu \mathrm{l}$ for absolute values and lower than $2 \%$ for CD $4 \%$. Our findings are similar to those reported by Manasa et al. who also found a satisfactory agreement with a mean bias of $-18 \mathrm{cell} / \mu \mathrm{l}$ [32]. The interclass agreement between Cyflow $^{\oplus}$ and FACSCalibur ${ }^{\circledR}$ was very good for both absolute count $(\mathrm{K}=0.83)$ and percentage $(\mathrm{K}=0.81)$, which means that $\mathrm{Cyflow}^{\oplus}$ could fairly classify patients in the same categories like FACSCalibur'.

Cyflow ${ }^{\bullet}$ showed satisfactory accuracy in all categories for CD4 percentage and absolute count, even for CD4 $>200$ cells/ $\mu$, precision was less good.

With Cyflow ${ }^{\circ}$, the preparation stability was good with unlabelled samples. This result shows that in case of incident or delayed delivery of samples, preparations labelled can be made from samples stored up to $48 \mathrm{~h}$. However, the labelled preparations are not stable and do not have to be used despite the manufacturer's recommendations.

\section{Operational characteristics}

The operational score of the 3 evaluated flow cytometers are not too different. They have many similarities but also some notable differences. FACSCount ${ }^{\circ}$ is a closed system using fully automated software. The software of the new platform of Guava also provides an automatic gating with the possibility to return to administrator profile to (i) refine the results when it does not give them in automatic mode or (ii) to reanalyse data acquired to get good results. However, the gating of the Cyflow is totally manual; requiring expertise in flow cytometry and computer science.

The number of samples that could be run per day is different for each evaluated cytometer but is sufficient for the operation of the sites to receive these equipments. More tests could be done with FACSCount ${ }^{\circ}$. This information is useful for the choice of a cytometer when there is only one operator per day.

The Unit packaging of the FACSCount reagent and automatic pipetting allows to achieve the optimal number of the test in the reagent kit. Guava ${ }^{\circ}$ and Cyflow ${ }^{\circ}$ do not have unit packaging of reagent per test, we noticed losses of 5 to $10 \%$ of reagent; which led to an increase in reagent supply.

FACSCount ${ }^{\circ}$ must increase his results archiving as it is limited to the 100 latest results and thermal paper print used degrades over time. On Cyflow $^{\oplus}$, there is no possibility to store reanalysed data. Therefore, to reprint a result, the operator has to do a new analysis on the original result, which can lead to differences, even minimal results delivered by the laboratory.

FACSCount $^{\oplus}$ and Cyflow $^{\star}$ are robust and resistant to voltage variations unlike Guava which is more sensitive and gives aberrant results.
Guava $^{\oplus}$ didn’t provide $16 \%$ of results in automatic mode for sample with low total lymphocyte count. FACSCount ${ }^{\circ}$ didn't provide CD4 percent for 19 patients (10.5\%). These difficulties could be cause by the automatic software of these cytometers which must be improved by manufacturers.

\section{Conclusion}

The Evaluation of three platforms of flow cytometers FACSCount $\mathrm{CD} 4 / \mathrm{CD} 4 \%^{\circ}$, Guava Auto CD4/CD $4 \%^{\circ}$ and Cyflow Counter CD4/ $\mathrm{CD} 4 \%{ }^{\circ}$ allowed to validate them in resource-limited settings. All these flow cytometers showed satisfactory performances but some technical and operational deficiencies. To choose a cytometer for a laboratory, preferences may be based on comparison between benefits and limits related to: the stability of the power supply, referral specimen management, delay of samples analysis, training of the operator and number of samples to process per day.

\section{Acknowledgements}

This article was proofread by Professor Luc KESTENS of the Institute of Tropical Medicine, Antwerpen.

\section{References}

1. UNAIDS (2014) The Gap Report.

2. World Health Organization (2005) Interim WHO Clinical Staging of HIV/AIDS and HIV/AIDS Case Definitions for Surveillance: Africa Region. World Health Organization.

3. Mellors JW, Muñoz A, Giorgi JV, Margolick JB, Tassoni CJ, et al. (1997) Plasma viral load and CD4+ lymphocytes as prognostic markers of HIV-1 infection. Ann Intern Med 126: 946-954.

4. O'Gorman MRG, Zijenah LS (2008) CD4 T cell measurements in the management of antiretroviral therapy A review with an emphasis on pediatric HIV-infected patients. Cytometry B Clin Cytom 74: S19-S26.

5. Fauci AS, Macher AM, Longo DL, Lane HC, Rook AH, et al. (1984) Acquired Immunodeficiency Syndrome: Epidemiologic, Clinical, Immunologic, and Therapeutic Considerations. Ann Intern Med 100: 92-106.

6. World Health Organization (2010) Antiretroviral Therapy for HIV Infection in Adults and Adolescents.

7. Diaw PA, Daneau G, Coly AA, Ndiaye BP, Wade D, et al. (2011) Multisite Evaluation of a Point-of-Care Instrument for CD4+ T-Cell Enumeration Using Venous and Finger-Prick Blood. The PIMA CD4. J Acquir Immune Defic Syndr 58: e103-e111.

8. Sukapirom K, Onlamoon N, Thepthai C, Polsrila K, Tassaneetrithep B, et al. (2011) Performance Evaluation of the Alere PIMA CD4 Test for Monitoring HIV-Infected Individuals in Resource-Constrained Settings. J Acquir Immune Defic Syndr 58: 141-147.

9. Wade D, Diaw PA, Daneau G, Diallo AA, Mboup S, et al. (2015) Laboratory and Field Evaluation of the Partec CyFlow MiniPOC for Absolute and Relative CD4 T-Cell Enumeration. PLoS One 10: e0116663.

10. Malagun M, Nano G, Chevallier C, Opina R, Sawiya G, et al. (2014) Multisite Evaluation of Point of Care CD4 Testing in Papua New Guinea. PLoS One 9: e112173.

11. Mtapuri-Zinyowera S, Chideme M, Mangwanya D, Mugurungi $O$, Gudukeya S, et al. (2010) Evaluation of the PIMA Point-of-Care CD4 Analyzer in VCT Clinics in Zimbabwe. J Acquir Immune Defic Syndr 55: $1-7$.

12. Mwau M, Adungo F, Kadima S, Njagi E, Kirwaye C, et al. (2013) Evaluation of PIMATM ${ }^{\circ}$ Point of Care Technology for CD4 T Cell Enumeration in Kenya. PLoS One 8: e67612. 
13. National Committee for Clinical Laboratory Standards (1998) Clinical application of flow cytometry: Immunophenotyping of lymphocytes. Approved guideline. NCCLS Document H42A囚 NCCLS.

14. Wade D, Daneau G, Aboud S, Vercauteren GH, Urassa WSK, et al. (2014) WHO multicenter evaluation of FACSCount CD4 and Pima CD4 T-cell count systems: instrument performance and misclassification of HIVinfected patients. J Acquir Immune Defic Syndr 66: e98-e107.

15. World Health Organization (2010) Technical Brief on CD4 Technologies. World Health.

16. Balakrishnan P, Solomon S, Mohanakrishnan J, Cecelia AJ, Kumarasamy $\mathrm{N}$, et al. (2006) A Reliable and Inexpensive Easy CD4 Assay for Monitoring HIV-Infected Individuals in Resource-Limited Settings. J Acquir Immune Defic Syndr 43: 23-26.

17. Dieye TN, Diaw PA, Daneau G, Wade D, Sylla Niang M, et al. (2011) Evaluation of a flow cytometry method for CD4 T cell enumeration based on volumetric primary CD4 gating using thermoresistant reagents. J Immunol Methods 372: 7-13.

18. Fryland M, Chaillet P, Zachariah R, Barnaba A, Bonte L, et al. (2006) The Partec CyFlow Counter ${ }^{\circledast}$ could provide an option for CD4+ T-cell monitoring in the context of scaling-up antiretroviral treatment at the district level in Malawi. Trans R Soc Trop Med Hyg 100: 980-985.

19. Lyamuya EF, Kagoma C, Mbena EC, Urassa WK, Pallangyo K, et al. (1996) Evaluation of the FACScount, TRAx CD4 and Dynabeads methods for CD4 lymphocyte determination. J Immunol Methods 195: 103-112.

20. Pattanapanyasat K, Phuang-Ngern $Y$, Lerdwana $S$, Wasinrapee $P$, Sakulploy N, et al. (2007) Evaluation of a single-platform microcapillary flow cytometer for enumeration of absolute CD4+ T-lymphocyte counts in HIV-1 infected Thai patients. Cytometry B Clin Cytom 72: 387-396.

21. Pattanapanyasat K, Phuang-Ngern Y, Sukapirom K, Lerdwana S, Thepthai C, et al. (2008) Comparison of 5 Flow Cytometric Immunophenotyping Systems for Absolute CD4+ T-Lymphocyte Counts in HIV-1-Infected Patients Living in Resource-Limited Settings. J Acquir Immune Defic Syndr 49: 339-347.

22. Spacek LA, Shihab HM, Lutwama F, Summerton J, Mayanja H, et al. (2006) Evaluation of a Low-Cost Method, the Guava EasyCD4 Assay, to
Enumerate CD4-Positive Lymphocyte Counts in HIV-Infected Patients in the United States and Uganda. J Acquir Immune Defic Syndr 41: 607-610.

23. Strauss K, Hannet I, Engels S, Shiba A, Ward DM, et al. (1996) Performance evaluation of the FACSCount System: a dedicated system for clinical cellular analysis. Cytometry 26: 52-59.

24. Young NL, Ponglertnapakorn P, Shaffer N, Srisak K, Chaowanachan T, et al. (1997) Clinical field site evaluation of the FACSCount for absolute $\mathrm{CD} 3+, \mathrm{CD} 3+\mathrm{CD} 4+$, and $\mathrm{CD} 3+\mathrm{CD} 8+$ cell count determinations in Thailand. Clin Diagn Lab Immunol 4: 783-786.

25. Pattanapanyasat K, Lerdwana S, Noulsri E, Chaowanachan T, Wasinrapee P, et al. (2005) Evaluation of a New Single-Parameter Volumetric Flow Cytometer (CyFlowgreen) for Enumeration of Absolute CD4+ T Lymphocytes in Human Immunodeficiency Virus Type 1-Infected Thai Patients. Clin Diagn Lab Immunol 12: 1416-1424.

26. Pattanapanyasat K, Sukapirom K, Kowawisatsut L, Thepthai C (2008) New BD FACSCountTM CD4 reagent system for simultaneous enumeration of percent and absolute CD4 T-lymphocytes in HIV-1infected pediatric patients. Cytometry B Clin Cytom 74: S98-S106.

27. Centers for Disease Control and Prevention (1992) 1993 revised classification system for HIV infection and expanded surveillance case definition for AIDS among adolescents and adults. MMWR Recomm Rep Morb Mortal Wkly Rep Recomm Rep Cent Dis Control 41: 1-19.

28. Bland JM, Altman DG (1999) Measuring agreement in method comparison studies. Stat Methods Med Res. 8: 135-160.

29. Bland JM, Altman DG (1986) Statistical methods for assessing agreement between two methods of clinical measurement. Lancet 1: 307-310.

30. Landis JR, Koch GG (1977) The measurement of observer agreement for categorical data. Biometrics 33: 159-174.

31. Cecelia AJ, Balakrishnan P, Mohanakrishnan, Venkatakrishnan B, Solomon S, et al. (2006) Effective evaluation of novel low-cost CD4 monitoring assays. J Immunol Methods 316: 158-62.

32. Manasa J, Musabaike H, Masimirembwa C, Burke E, Luthy R, et al. (2007) Evaluation of the Partec Flow Cytometer against the BD FACSCalibur System for Monitoring Immune Responses of Human Immunodeficiency Virus-Infected Patients in Zimbabwe. Clin Vaccine Immunol 14: 293-298. 